\title{
CAPTAÇÃO E APROVEITAMENTO DA RADIAÇÃO SOLAR PELAS CULTURAS DA SOJA E DO FEIJÃO E POR PLANTAS DANINHAS ${ }^{(1)}$
}

\author{
JOSÉ BARBOSA DOS SANTOS ${ }^{(2)}$; SÉRGIO DE OLIVEIRA PROCÓPIO ${ }^{(3)}$; \\ ANTÔNIO ALBERTO DA SILVA ${ }^{(4)}$; LUIZ CLÁUDIO COSTA ${ }^{(5)}$
}

\begin{abstract}
RESUMO
Com o objetivo de desenvolver técnicas para a criação de um programa de manejo integrado de plantas daninhas (MIPD), avaliou-se neste trabalho, em condições de campo, o desempenho das culturas do feijão (Phaseolus vulgaris L.) e da soja [Glycine max (L.) Merrill] e das plantas daninhas picão-preto (Bidens pilosa L.), dois biótipos de leiteiro (Euphorbia heterophylla L.) (sensível e resistente a herbicidas inibidores da enzima ALS), e carrapicho-beiço-de-boi [Desmodium tortuosum (SW.) DC.], quanto à eficiência na captação e ao aproveitamento da radiação solar, por meio do cálculo dos índices taxa de produção de biomassa seca total $\left(\mathrm{C}_{\mathrm{t}}\right)$, taxa de produção de biomassa seca foliar $\left(\mathrm{C}_{\mathrm{f}}\right)$, uso eficiente da radiação (î), taxa de assimilação líquida $\left(\mathrm{E}_{\mathrm{A}}\right)$, área foliar específica $\left(\mathrm{S}_{\mathrm{A}}\right)$, índice de área foliar $(\mathrm{L})$, razão de massa foliar $\left(\mathrm{F}_{\mathrm{W}}\right)$ e razão de área foliar $\left(\mathrm{F}_{\mathrm{A}}\right)$. O experimento foi desenvolvido em Argissolo Vermelho-Amarelo em Viçosa, MG. Não se observou diferença para todas as características avaliadas entre os biótipos de $E$. heterophylla. A soja apresentou a maior taxa de produção de biomassa seca total ao longo do seu ciclo e também o maior índice de área foliar evidenciando sua maior capacidade em captar luz e em sombrear plantas competidoras. O feijão, sobretudo após o florescimento, foi a planta mais eficaz em drenar seus fotoassimilados para a formação de folhas. A soja apresentou maior eficiência em converter a radiação interceptada em biomassa.
\end{abstract}

Palavras-chave: planta daninha, competição, manejo integrado, uso eficiente da radiação.

\section{ABSTRACT \\ CAPTURE AND UTILIZATION OF SOLAR RADIATION BY THE SOYBEAN AND COMMON BEAN CROPS AND BY WEEDS}

\begin{abstract}
Aiming to develop techniques for the establishment of a Weed Integrated Management Program, the performance of common bean (Phaseolus vulgaris L.) and soybean (Glycine max (L.) Merrill) and of weeds Bidens pilosa L., Euphorbia heterophylla L. (two biotypes), sensitive and resistant to ALS inhibitor herbicides and [ Desmodium tortuosum (SW.) DC.], was evaluated in relation to their efficiency in capturing and utilizing solar radiation. The following indices were calculated: total dry biomass production rate $\left(C_{t}\right)$, leaf dry biomass production rate $\left(C_{f}\right)$, radiation efficient use $(x)$, net assimilation rate $\left(E_{A}\right)$, specific leaf area $\left(\mathrm{S}_{\mathrm{A}}\right)$, leaf area index $(\mathrm{L})$, leaf matter ratio $\left(\mathrm{F}_{\mathrm{W}}\right)$ and leaf area ratio $\left(\mathrm{F}_{\mathrm{A}}\right)$. No difference was observed for all characteristics evaluated among E. heterophylla biotypes. Soybean showed the highest rate of total dry biomass production along its cycle and also the highest leaf area index, indicating its greater capacity in capturing light and providing shade to competitive plants. Especially after flowering, common bean was the most efficient in draining its photoassimilates for leaf formation. Soybean showed greater efficiency in converting radiation intercepted in the biomass.
\end{abstract}

Key words: Weed, competition, integrated management, efficient use of radiation.

$\left({ }^{1}\right)$ Recebido para publicação em 4 de outubro de 2001 e aceito em 31 de outubro de 2002.

( $\left.{ }^{2}\right)$ Mestrando em Fitotecnia, Universidade Federal de Viçosa (UFV), 36571-000, Viçosa (MG). E-mail: jbarbosa2000@yahoo.com.br

$\left({ }^{3}\right)$ Doutorando em Fitotecnia, UFV. E-mail: procopio@alunos.ufv.br

( $\left.{ }^{4}\right)$ Departamento de Fitotecnia, UFV. E-mail: aasilva@mail.ufv.br

$\left({ }^{5}\right)$ Departamento de Engenharia Agrícola, UFV. E-mail: 1.costa@mail.ufv.br 


\section{INTRODUÇÃO}

Considerando a importância da soja e do feijão para a economia brasileira, torna-se necessário o investimento em tecnologia, visando à redução de custos de produção para aumentar o lucro dos produtores e para a obtenção de produto final de melhor qualidade que não prejudique a saúde humana e o ambiente.

Analisando-se a cultura do feijão, observa-se que, em média, $20 \%$ a $30 \%$ do seu custo total de produção refere-se ao controle de plantas daninhas e no caso da soja, esse valor, com freqüência, está acima dos 30\% (Silva et al., 2000). Por este motivo, estudos mais elaborados sobre a morfologia e a fisiologia destas culturas e das principais espécies de plantas daninhas infestantes são fundamentais na tentativa de se reduzir o uso de herbicidas e, conseqüentemente, os custos e o impacto ambiental negativo provocado pelo emprego desses insumos químicos. Todavia, observa-se a falta de informações dessas áreas na literatura especializada, especialmente para as principais espécies de plantas daninhas de ocorrência no Brasil.

A maioria dos estudos em que se avaliaram os efeitos da competição entre as plantas daninhas e as culturas (VIEIRA, 1970; BLANCO et al., 1973; CoBle et al., 1981; MASCARENHAS, 1982; VARGAS et al., 1999; SANTOS e SILVA, 2000; Mello et al. 2001), teve como objetivo apenas verificar o efeito dessas plantas na produtividade e/ou no crescimento (acúmulo de biomassa seca) das culturas, ou seja, quantificar as conseqüências. Entretanto, as causas relacionadas às aptidões fisiológicas específicas de cada planta não são praticamente estudadas.

Os fatores que determinam a maior competitividade das plantas daninhas sobre as culturas são seu porte e sua arquitetura; a maior velocidade de germinação e estabelecimento da plântula; a maior velocidade do crescimento e a maior extensão do sistema radicular; a menor suscetibilidade das espécies daninhas às intempéries climáticas, como veranico e geadas e a maior capacidade de produção e liberação de substâncias químicas com propriedades alelopáticas (SILVA et al., 2000).

Dentre as espécies de plantas daninhas dicotiledôneas infestantes das culturas anuais de grande importância econômica, destacam-se Euphorbia heterophylla, Bidens pilosa e Desmodium tortuosum, pela agressividade, capacidade competitiva e intensidade de ocorrência.

Biótipos de Euphorbia heterophylla, resistentes aos herbicidas inibidores da ALS, foram identificados em lavouras de soja nos Estados do Rio Grande do Sul, Paraná e Mato Grosso do Sul, onde esses produtos são empregados há mais de seis anos (VARGAS et al., 1999). Alguns trabalhos mostraram não haver diferença competitiva entre os biótipos sensíveis e resistentes de leiteiro quanto à morfologia, duração do ciclo e potencial de competição com a cultura da soja (VARGAS et al., 1999; Vidal e Trezzi, 2000 e Santos e Silva, 2000).

O objetivo do trabalho foi avaliar a captação e o aproveitamento da radiação solar pelas culturas da soja e do feijão e pelas espécies de plantas daninhas $E$. heterophylla (resistente e suscetível aos herbicidas inibidores da ALS), B. pilosa e D. tortuosum, por meio do cálculo dos índices de crescimento: Taxa de produção de biomassa seca total $\left(C_{t}\right)$, taxa de produção de biomassa seca foliar $\left(C_{\mathrm{f}}\right)$, índice de área foliar $(\mathrm{L})$, área foliar específica $\left(\mathrm{S}_{\mathrm{A}}\right)$, razão de massa foliar $\left(\mathrm{F}_{\mathrm{w}}\right)$, razão de área foliar $\left(\mathrm{F}_{\mathrm{A}}\right)$, taxa assimilatória líquida $\left(\mathrm{E}_{\mathrm{a}}\right)$ e uso eficiente da radiação $(\xi)$.

\section{MATERIAL E MÉTODOS}

O experimento foi realizado no campo experimental, do Departamento de Fitotecnia da Universidade Federal de Viçosa (UFV), em Argissolo Vermelho-Amarelo, fase terraço, de outubro de 2000 a fevereiro de 2001.

Os tratamentos foram compostos pelas culturas de soja (cultivar UFV-19) e de feijão (cultivar Pérola) e pelas espécies de plantas daninhas E. heterophylla (um biótipo suscetível aos herbicidas inibidores da enzima ALS, coletado em Minas Gerais e outro resistente, coletado no Rio Grande do Sul), B. pilosa e D. tortuosum. O delineamento experimental utilizado foi o de blocos casualizados, com quatro repetições, totalizando 24 parcelas. Cada parcela experimental constou de $10 \mathrm{~m}$ de largura por $10 \mathrm{~m}$ de comprimento, contendo 16 fileiras de uma das espécies avaliadas.

Após a calagem, realizada 90 dias antes da instalação do experimento, fez-se o preparo convencional do solo com uma aração e duas gradagens. A adubação de plantio foi realizada de maneira uniforme em toda área experimental, conforme análise do solo, considerando-se as necessidades da cultura do feijão.

A semeadura, tanto para as culturas quanto para as plantas daninhas, foi manual. Após a emergência das plantas, foi realizado desbaste deixando-se cinco plantas por metro de sulco em todos os tratamentos. Todas as parcelas foram mantidas no limpo por meio de capinas manuais. Suplemento de irrigação por aspersão convencional foi realizada uniformemente em toda área experimental em períodos de veranico. 
Quinzenalmente, após o desbaste das plantas, efetuaram-se medições da radiação fotossinteticamente ativa (RFA) em dois pontos dos dosséis: acima e abaixo, com o uso de um ceptômetro (Delta T- Devices), colocado perpendicular às linhas das plantas. Quinzenalmente, também, três plantas foram colhidas ao acaso por parcela, para a determinação do número de folhas por planta e da área foliar $\left(\mathrm{A}_{\mathrm{f}}\right)$ por meio de um medidor eletrônico de área foliar, bem como a biomassa seca das plantas (folhas, raízes, caules e partes reprodutivas) após secagem em estufa a $75{ }^{\circ} \mathrm{C}$ por 72 horas. Independentemente do intervalo de amostragens e da coleta dos dados primários (quinzenal), poucos dias antes do início do florescimento e da maturação fisiológica das sementes, realizou-se uma amostragem e coleta dos dados em todas as parcelas. Foi considerado o início do florescimento quando, em torno, de $50 \%$ das plantas apresentavam pelo menos uma flor aberta.

Os dados meteorológicos diários de temperatura do ar, precipitação, insolação e umidade relativa do ar (Figuras 1 e 2) foram obtidos da Estação Meteorológica do Departamento de Engenharia Agrícola instalada a, aproximadamente, $400 \mathrm{~m}$ da área experimental.

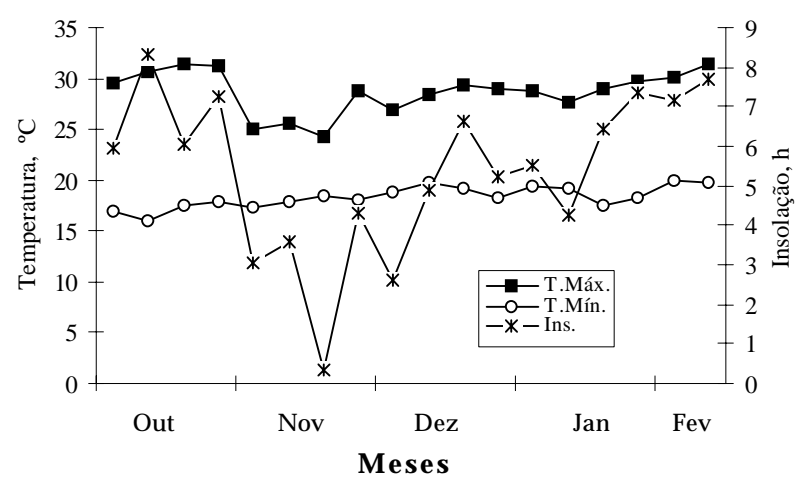

Figura 1. Médias semanais de temperatura máxima (T. Máx), temperatura mínima (T. Mín.) e insolação (Ins.), de outubro de 2000 a fevereiro de 2001.

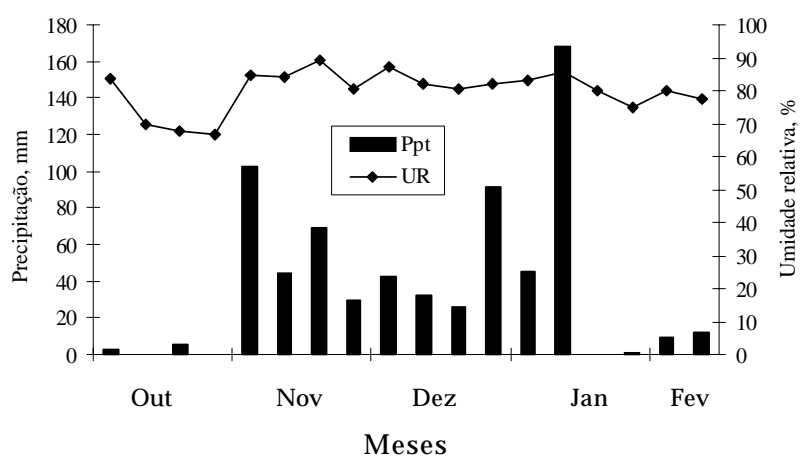

Figura 2. Médias semanais de precipitação (Ppt) e umidade relativa (UR), de outubro de 2000 a fevereiro de 2001 .
A partir dos dados primários de biomassa seca total em $g\left(W_{t}\right)$, biomassa seca das folhas em $g\left(W_{f}\right)$, área foliar em $\mathrm{m}^{2}\left(\mathrm{~A}_{\mathrm{f}}\right)$ e radiação fotossinteticamente ativa interceptada em MJ $\left(R_{i}\right)$ foram calculados os seguintes índices de crescimento: Taxa de produção de biomassa seca total $\left(\mathrm{C}_{\mathrm{t}}=\mathrm{dW}_{\mathrm{t}} / \mathrm{d}_{\mathrm{t}}\right)$; taxa de produção de biomassa seca foliar $\left(C_{\mathrm{f}}=\mathrm{dW}_{\mathrm{f}} / \mathrm{dt}\right)$; índice de área foliar $\left(L=A_{f} / S_{t}\right)$, onde $S_{t}$ é a superfície do terreno em $\mathrm{m}^{2}$; área foliar específica $\left(\mathrm{S}_{\mathrm{A}}=\mathrm{A}_{\mathrm{f}} / \mathrm{W}_{\mathrm{f}}\right)$; razão de massa foliar $\left(\mathrm{F}_{\mathrm{W}}=\mathrm{W}_{\mathrm{f}} / \mathrm{W}_{\mathrm{t}}\right)$; razão de área foliar $\left(\mathrm{F}_{\mathrm{A}}\right.$ $\left.=\mathrm{S}_{\mathrm{A}} \cdot \mathrm{F}_{\mathrm{W}}\right)$; taxa assimilatória líquida $\left(\mathrm{EA}=1 / \mathrm{A}_{\mathrm{f}} \cdot \mathrm{dW}_{\mathrm{t}} / \mathrm{dt}\right)$ e uso eficiente da radiação $\left(\xi=W_{t} / R_{i}\right)$.

Terminados os cálculos dos índices de crescimento, esses foram submetidos à análise da variância e as características significativas foram submetidas ao teste de Tukey a $5 \%$ de probabilidade.

\section{RESULTADOS E DISCUSSÃO}

Analisando-se o quadro 1, verificou-se que a soja foi a espécie que apresentou o maior valor de $W_{t}$ e de $C_{t}$ tanto antes como após o florescimento. Entre as plantas daninhas D. tortuosum acumulou maior $\mathrm{W}_{\mathrm{t}}$ na fase vegetativa, enquanto $B$. pilosa apresentou maior $W_{t}$ após o florescimento. A soja foi a espécie que, também, demonstrou maior $W_{\mathrm{f}}$ nas duas fases avaliadas, contudo, não diferindo na fase vegetativa do $\mathrm{W}_{\mathrm{f}}$ apresentado por D. tortuosum (Quadro 1). Também, o $C_{\mathrm{f}}$ da soja na fase vegetativa não diferiu do $C_{\mathrm{f}}$ do $D$. tortuosum.

A produção de $W_{\mathrm{f}}$ na soja durante a fase vegetativa foi, aproximadamente, 2,4 vezes maior do que no feijão. Todavia, os valores de $C_{f}$ entre a soja e o feijão não diferiram em ambos os períodos avaliados, mostrando que o maior valor de $\mathrm{W}_{\mathrm{f}}$ da soja em relação ao feijão deve-se ao maior número de dias que essa espécie permanece em crescimento. Não se detectaram diferenças entre os dois biótipos de $E$. heterophylla quanto ao $\mathrm{W}_{\mathrm{t}}, \mathrm{C}_{\mathrm{t}}, \mathrm{W}_{\mathrm{f}}$ e $\mathrm{C}_{\mathrm{f}}$ em ambas as épocas estudadas.

Quando se compara a razão de massa foliar $\left(\mathrm{F}_{\mathrm{w}}\right)$ na fase vegetativa (Quadro 2 ), observa-se que não houve diferenças significativas entre as espécies avaliadas. Contudo, após o florescimento, o feijão foi a planta que mais drenou seus fotoassimilados para a formação de folhas, apresentando $F_{w}$ de 0,300 , o que significa que $30 \%$ da biomassa seca da planta está na forma de folhas nessa fase (Quadro 2). Os biótipos de E. heterophylla, antes do florescimento, apresentaram valores semelhantes de $\mathrm{F}_{\mathrm{w}}(0,501$ para o biótipo resistente e 0,521 para o biótipo sensível aos herbicidas inibidores de ALS) sendo o dobro dos valores encontrado por VidAL e TREZZI (2000), que compararam biótipos dessa planta de quatro diferentes regiões do Rio Grande do Sul. 
Quadro 1. Valores máximos de biomassa seca total $\left(W_{t}\right)$, biomassa seca de folhas $\left(W_{\mathrm{f}}\right)$, taxa de produção de biomassa seca total $\left(C_{t}\right)$ e taxa de produção de biomassa seca foliar $\left(C_{f}\right)$, antes e após florescimento, para plantas de feijão e soja, e algumas espécies de plantas daninhas. Viçosa (MG), 2001

\begin{tabular}{|c|c|c|c|c|c|c|c|c|}
\hline \multirow{2}{*}{ Espécies vegetais } & \multicolumn{4}{|c|}{ Antes do florescimento } & \multicolumn{4}{|c|}{ Após o florescimento } \\
\hline & $\mathrm{W}_{\mathrm{t}}$ & $\mathrm{W}_{\mathrm{f}}$ & $\mathrm{C}_{\mathrm{t}}$ & $\mathrm{C}_{\mathrm{f}}$ & $\mathrm{W}_{\mathrm{t}}$ & $\mathrm{W}_{\mathrm{f}}$ & $\mathrm{C}_{\mathrm{t}}$ & $\mathrm{C}_{\mathrm{f}}$ \\
\hline \multirow[b]{2}{*}{ Phaseolus vulgaris } & \multicolumn{2}{|c|}{ g.planta ${ }^{-1}$} & \multicolumn{2}{|c|}{ — g.planta ${ }^{-1} \mathrm{dia}^{-1}$} & \multicolumn{2}{|c|}{ g.planta ${ }^{-1}$} & \multicolumn{2}{|c|}{ - g.planta ${ }^{-1} \mathrm{dia}^{-1}-$} \\
\hline & $3,372 \mathrm{c}$ & $1,857 \mathrm{~b}$ & $0,094 \mathrm{bc}$ & $0,052 \mathrm{ab}$ & $30,922 \mathrm{c}$ & $9,276 \mathrm{~b}$ & $0,349 \mathrm{bc}$ & $0,109 \mathrm{a}$ \\
\hline Glycine max & $21,585 \mathrm{a}$ & 4,513 a & 0,379 a & 0,079 a & $114,349 \mathrm{a}$ & 17,953 a & $1,167 \mathrm{a}$ & $0,135 \mathrm{a}$ \\
\hline $\begin{array}{l}\text { Euphorbia heterophylla } \\
\left.\text { (resistente }^{*}\right)\end{array}$ & $0,753 \mathrm{c}$ & $0,367 c$ & $0,019 \mathrm{c}$ & $0,009 \mathrm{c}$ & $21,492 \mathrm{c}$ & $1,396 \mathrm{~b}$ & $0,298 \mathrm{bc}$ & $0,013 \mathrm{c}$ \\
\hline $\begin{array}{l}\text { Euphorbia heterophylla } \\
\left(\text { sensivel }^{*}\right)\end{array}$ & $0,813 \mathrm{c}$ & $0,369 \mathrm{c}$ & $0,020 \mathrm{c}$ & $0,009 \mathrm{c}$ & $27,609 \mathrm{c}$ & $1,435 \mathrm{~b}$ & $0,236 \mathrm{c}$ & $0,013 \mathrm{c}$ \\
\hline Bidens pilosa & $1,113 \mathrm{c}$ & $0,631 \mathrm{c}$ & $0,025 \mathrm{c}$ & $0,014 \mathrm{bc}$ & $59,052 \mathrm{~b}$ & $2,956 \mathrm{~b}$ & $0,372 \mathrm{~b}$ & $0,025 \mathrm{~b}$ \\
\hline Desmodium tortuosum & $11,410 \mathrm{~b}$ & $3,971 \mathrm{a}$ & $0,148 \mathrm{~b}$ & $0,052 \mathrm{ab}$ & $34,410 \mathrm{c}$ & $4,576 \mathrm{~b}$ & $0,271 \mathrm{bc}$ & $0,033 \mathrm{~b}$ \\
\hline
\end{tabular}

*: Biótipo resistente e sensível aos herbicidas inibidores da enzima ALS.

Médias seguidas de mesma letra na coluna não diferem pelo teste de Tukey a $5 \%$ de probabilidade.

Dentre as espécies estudadas, B. pilosa, os biótipos de E. heterophylla e a soja foram as que apresentaram maior valor de $S_{A}$ na fase vegetativa (Quadro 2), ou seja, suas folhas foram menos espessas, o que favorece a eficiência fotossintética das plantas, por diminuir as barreiras internas da planta à entrada tanto da luz como do $\mathrm{CO}_{2}$. Após o florescimento, o SA de todas as espécies não diferiu, sendo observado declínio do valor de $S_{A}$ para todas as plantas, o que significa que a espessura das folhas aumentou ao longo do tempo. O produto de $\mathrm{S}_{\mathrm{A}}$ e $\mathrm{F}_{\mathrm{W}}$ resulta no índice razão de área foliar $\left(\mathrm{F}_{\mathrm{A}}\right)$, que fornece uma idéia do "enfolhamento" das plantas, isto é, indica a razão entre a área foliar e a biomassa seca total das plantas. Segundo Benincasa (1988), com o crescimento e desenvolvimento das plantas aumenta-se o autosombreamento das folhas inferiores e a tendência é diminuir a área foliar a partir de certo período por indução à senescência destas folhas. As plantas daninhas B. pilosa e os dois biótipos de E. heterophylla apresentaram os maiores valores de $\mathrm{F}_{\mathrm{A}}$ antes do florescimento (Quadro 2). Tal fato pode sugerir uma adaptação dessas plantas na captação de luz nas fases iniciais do ciclo.

Quadro 2. Valores máximos de índice de área foliar $(\mathrm{L})$, razão de massa foliar $\left(\mathrm{F}_{\mathrm{W}}\right)$, área foliar específica $\left(\mathrm{S}_{\mathrm{A}}\right)$ e razão de área foliar $\left(\mathrm{F}_{\mathrm{A}}\right)$, antes e após o florescimento, para plantas de feijão e de soja, e algumas espécies de plantas daninhas. Viçosa (MG), 2001

\begin{tabular}{|c|c|c|c|c|c|c|c|c|}
\hline \multirow{2}{*}{ Espécies vegetais } & \multicolumn{4}{|c|}{ Antes do florescimento } & \multicolumn{4}{|c|}{ Após o florescimento } \\
\hline & \multirow[t]{2}{*}{$\mathrm{L}$} & \multirow{2}{*}{$\frac{F_{W}}{g \cdot g^{-1}}$} & $\mathrm{~S}_{\mathrm{A}}$ & $\mathrm{F}_{\mathrm{A}}$ & $\mathrm{L}$ & $\mathrm{F}_{\mathrm{W}}$ & $\mathrm{S}_{\mathrm{A}}$ & $\mathrm{F}_{\mathrm{A}}$ \\
\hline & & & \multicolumn{2}{|c|}{$\mathrm{m}^{2} \cdot \mathrm{g}^{-1}$} & & g.g ${ }^{-1}$ & \multicolumn{2}{|c|}{$\mathrm{m}^{2} \cdot \mathrm{g}^{-1}$} \\
\hline Phaseolus vulgaris & $0,246 \mathrm{c}$ & 0,557 a & $0,016 \mathrm{~b}$ & $0,008 \mathrm{c}$ & $0,714 \mathrm{~b}$ & $0,300 \mathrm{a}$ & $0,010 \mathrm{a}$ & $0,0030 \mathrm{a}$ \\
\hline Glycine max & $0,815 \mathrm{a}$ & $0,385 \mathrm{a}$ & $0,029 \mathrm{ab}$ & $0,011 \mathrm{bc}$ & $4,333 \mathrm{a}$ & $0,207 \mathrm{~b}$ & $0,009 \mathrm{a}$ & $0,0019 \mathrm{~b}$ \\
\hline $\begin{array}{l}\text { Euphorbia heterophylla } \\
\text { (resistente*) }\end{array}$ & $0,115 \mathrm{c}$ & $0,501 \mathrm{a}$ & $0,045 \mathrm{a}$ & $0,020 \mathrm{a}$ & $0,508 \mathrm{~b}$ & $0,051 \mathrm{~d}$ & $0,013 \mathrm{a}$ & $0,0007 \mathrm{c}$ \\
\hline $\begin{array}{l}\text { Euphorbia heterophylla } \\
\text { (sensível*) }\end{array}$ & $0,125 \mathrm{c}$ & $0,521 \mathrm{a}$ & $0,031 \mathrm{ab}$ & $0,016 \mathrm{ab}$ & $0,238 \mathrm{~b}$ & $0,052 \mathrm{~cd}$ & $0,014 \mathrm{a}$ & $0,0007 \mathrm{c}$ \\
\hline Bidens pilosa & $0,203 \mathrm{c}$ & 0,567 a & $0,033 \mathrm{ab}$ & $0,018 \mathrm{a}$ & $0,633 \mathrm{~b}$ & $0,050 \mathrm{~d}$ & $0,013 \mathrm{a}$ & $0,0007 \mathrm{c}$ \\
\hline Desmodium tortuosum & $0,519 \mathrm{~b}$ & $0,363 \mathrm{a}$ & $0,018 \mathrm{~b}$ & $0,006 \mathrm{c}$ & $1,066 \mathrm{~b}$ & $0,133 \mathrm{bc}$ & $0,013 \mathrm{a}$ & $0,0017 \mathrm{~b}$ \\
\hline
\end{tabular}

*: Biótipo resistente e sensível aos herbicidas inibidores da enzima ALS.

Médias seguidas de mesma letra na coluna não diferem pelo teste de Tukey a 5\% de probabilidade. 
$\mathrm{O}$ feijão apresentou o maior $\mathrm{F}_{\mathrm{A}}$ após o florescimento, o que sugere possível especialização da planta em realizar fotossíntese para o enchimento de grãos, induzida pelo melhoramento genético antrópico. Os biótipos de E. heterophylla não diferiram quanto ao $\mathrm{F}_{\mathrm{W}}, \mathrm{F}_{\mathrm{A}}$ e $\mathrm{S}_{\mathrm{A}}$. O feijão apresentou valor de $\mathrm{L}$, aproximadamente, três vezes menor que o da soja na fase vegetativa. PengelLy et al (1999), trabalhando com soja e Vigna trilobata, encontraram valores de L de 4,3 e 0,6 , respectivamente, aos 49 dias após a semeadura, confirmando a superioridade da soja.

Após o florescimento, o valor de L encontrado para a soja foi, aproximadamente, quatro vezes maior que o encontrado para D. tortuosum, (Quadro 2). O L apresentado pelos biótipos de E. heterophylla não diferiu estatisticamente. A taxa assimilatória líquida $\left(E_{A}\right)$ observada para o feijão, antes do florescimento, foi superior a todas as demais espécies, inclusive a soja (aproximadamente $50 \%$ a mais) (Quadro 3), ou seja, nesta fase o feijão foi a espécie que produziu mais biomassa seca a cada unidade de área foliar. Isso pode ajudar a explicar o rápido fechamento do dossel observado para essa cultura, nos períodos iniciais do ciclo.

Os valores de $\mathrm{E}_{\mathrm{A}}$ para os biótipos de $E$. heterophylla, na fase vegetativa, não diferiram, sendo em média, de 1,600 g.m ${ }^{-2}$.dia ${ }^{-1}$. Valores semelhantes foram também constatados por VIDAL e TREZZI (2000), em avaliação aos 33 dias após a emergência. Após o florescimento, entretanto, $D$. tortuosum mostrou o menor $\mathrm{E}_{\mathrm{A}}$, não diferindo estatisticamente do observado pelo biótipo sensível de E. heterophylla, de B. pilosa e da soja (Quadro3).

$\mathrm{O} \xi$ representa o aproveitamento da radiação fotossinteticamente ativa interceptada por cada espécie, ou seja, a eficiência da planta em transformar energia solar em energia química. A soja foi a espécie avaliada que apresentou o maior valor de $\xi$ tanto na fase vegetativa, como na reprodutiva (Quadro 3 e Figura 3), sendo a espécie vegetal com maior resposta em biomassa seca para cada $\mathrm{MJ}$ de radiação fotossinteticamente ativa interceptada. $\mathrm{O} \xi$ médio visto por Pengelly et al. (1999) para as plantas soja foi de 0,89 g. $\mathrm{MJ}^{-1}$, valor este menor do que o encontrado no trabalho 2,28 e 2,54 g. $\mathrm{MJ}^{-1}$, respectivamente, antes do florescimento e após o florescimento.

Todas as espécies, com exceção do feijão, aumentaram o $\xi$ após o florescimento, o que difere dos resultados de KUMAR et al (1996) que avaliaram o $\xi$ de plantas de mamona (Ricinus communis L.), antes e após o início da floração, encontrando valores que variaram de 1,12 a 1,44 e de 0,76 a $1,36\left(\mathrm{~g} . \mathrm{MJ}^{-1}\right)$, respectivamente, ou seja, os valores diminuíram após o florescimento. Por outro lado, CONFALONE et al. (1997) observaram que o valor da eficiência no uso da radiação para a cultura da soja, em condições ótimas, foi em média de $1,73 \mathrm{~g}$. $\mathrm{MJ}^{-1}$ e permaneceu relativamente constante nas diferentes fases fenológicas. Tanto o $\mathrm{E}_{\mathrm{A}}$ como o $\xi$ dos biótipos de $E$. heterophylla não diferiram estatisticamente.

As vantagens competitivas das plantas daninhas, frente às culturas muitas vezes preconizadas na literatura, devem ser analisadas com cuidado, pois existe grande diversidade de plantas daninhas com características fisiológicas diferentes.

Com relação às plantas daninhas avaliadas no experimento, a superioridade na competição, algumas vezes observada no campo frente às culturas, pode ser devido à ocorrência de alta densidade dessas invasoras presentes na área, ou a vantagens competitivas frente à obtenção e aproveitamento de outros recursos como água ou nutrientes minerais do solo.

Quadro 3. Valores máximos de taxa de assimilação líquida $\left(\mathrm{E}_{\mathrm{A}}\right)$ e uso eficiente da radiação ( $\xi$ ) antes e após o florescimento, para plantas de feijão e de soja, e algumas espécies de plantas daninhas. Viçosa (MG), 2001

\begin{tabular}{|c|c|c|c|c|}
\hline \multirow{2}{*}{ Espécies vegetais } & \multicolumn{2}{|c|}{ Antes do florescimento } & \multicolumn{2}{|c|}{ Após o florescimento } \\
\hline & $\mathrm{E}_{\mathrm{A}}$ & $\xi$ & $\mathrm{E}_{\mathrm{A}}$ & $\xi$ \\
\hline & g.m ${ }^{-2} \cdot$ dia $^{-1}$ & g.MJ ${ }^{-1}$ & g.m $\mathrm{m}^{-2} \cdot \mathrm{dia}^{-1}$ & g.MJ ${ }^{-1}$ \\
\hline Phaseolus vulgaris & $3,37 \mathrm{a}$ & $1,96 \mathrm{~b}$ & $5,67 \mathrm{a}$ & $1,83 \mathrm{~b}$ \\
\hline Glycine max & $2,17 b$ & $2,28 \mathrm{a}$ & $4,56 \mathrm{ab}$ & $2,53 \mathrm{a}$ \\
\hline Euphorbia heterophylla (resistente*) & $1,56 \mathrm{c}$ & $0,87 \mathrm{c}$ & $6,36 \mathrm{a}$ & $1,22 \mathrm{c}$ \\
\hline Euphorbia heterophylla (sensível*) & $1,74 \mathrm{bc}$ & $1,05 \mathrm{c}$ & $5,37 \mathrm{ab}$ & $1,29 \mathrm{c}$ \\
\hline Bidens pilosa & $0,83 \mathrm{~d}$ & $0,96 \mathrm{c}$ & $4,74 \mathrm{ab}$ & $1,69 \mathrm{bc}$ \\
\hline Desmodium tortuosum & $2,20 \mathrm{~b}$ & $0,72 \mathrm{c}$ & $3,41 \mathrm{~b}$ & $1,79 \mathrm{~b}$ \\
\hline
\end{tabular}

*: Biótipo resistente e sensível aos herbicidas inibidores da enzima ALS.

Médias seguidas de mesma letra na coluna não diferem pelo teste de Tukey a 5\% de probabilidade. 

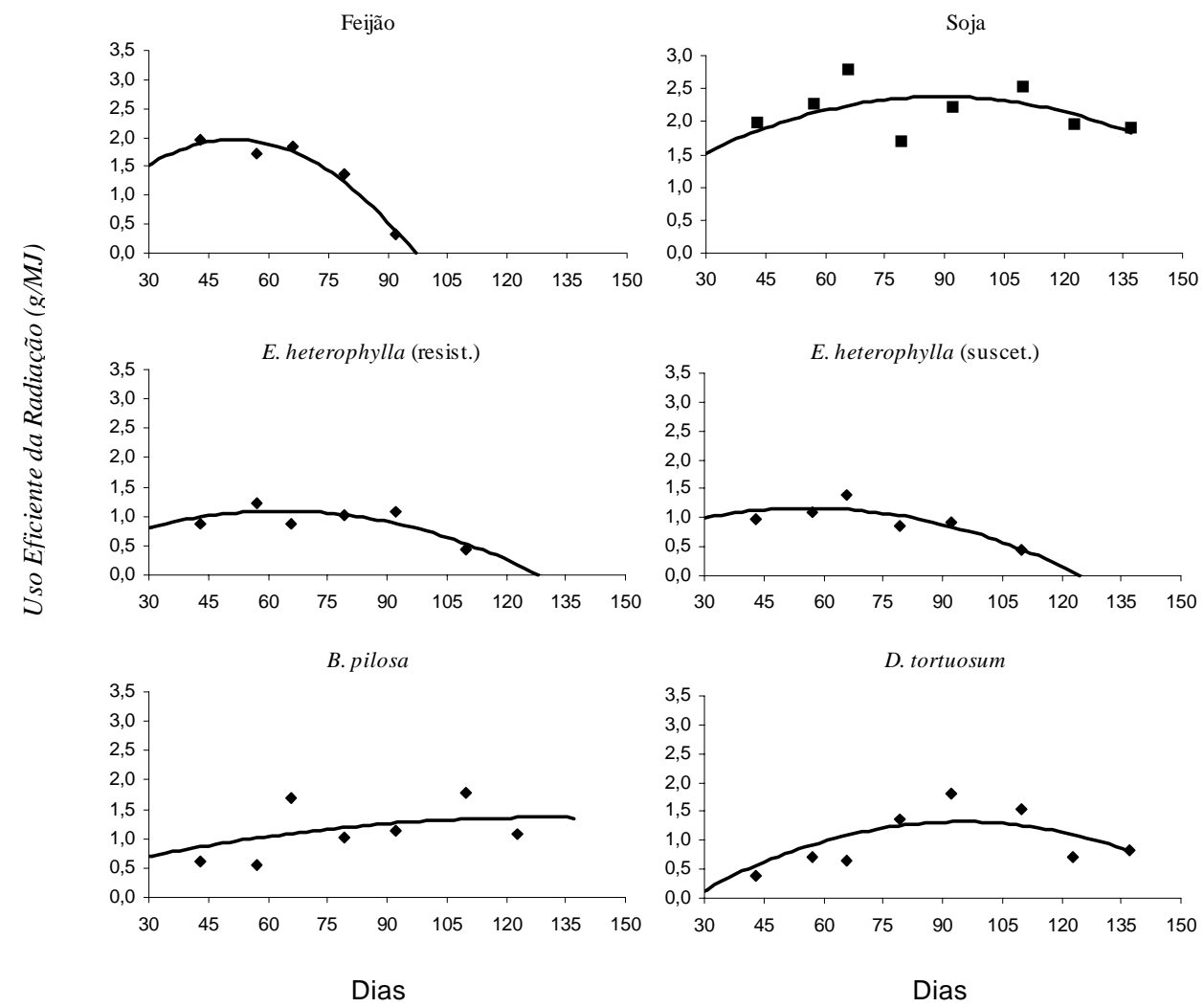

Figura 3. Uso eficiente da radiação encontrado durante o ciclo das espécies: feijão, soja, Euphorbia heterophylla resistente e sensível aos herbicidas inibidores de ALS, Bidens pilosa e Desmodium tortuosum.

\section{CONCLUSÕES}

1. Os biótipos de E. heterophylla, sensível ou resistente aos herbicidas inibidores da enzima ALS, apresentaram equivalência competitiva entre eles.

2. A soja apresentou a maior taxa de produção de biomassa seca total ao longo do seu ciclo e também o maior índice de área foliar, evidenciando maior capacidade em captar luz e em sombrear plantas competidoras.

3. O feijão, principalmente após o florescimento, foi a espécie mais eficiente em drenar seus fotoassimilados para a formação de folhas.

4. A soja apresentou maior eficiência em converter a radiação interceptada em biomassa.

\section{AGRADECIMENTOS}

À empresa Syngenta e ao CNPq pelo apoio financeiro.

\section{REFERÊNCIAS BIBLIOGRÁFICAS}

BENINCASA, M.M.P. Análise de crescimento de plantas. Jaboticabal: FUNEP, 1988. 42p.

BLANCO, H.G.; OLIVEIRA, D.A.; ARAÚJO, J.B.M.; GRASSI, N. Observações sobre o período em que as plantas daninhas competem com a soja (Glycine max (L.) Merr.). O Biológico, São Paulo, v.39, n.2, p.31-35, 1973.

COBLE, H. D., WILLIANS, F.M., RITLE, R.L. Common ragweed (Ambrosia artemisiifolia) interference in soybeans (Glycine max). Weed Science, Lawrence, v.29, n.3, p.339-342, 1981.

CONFALONE, A.; COSTA, L.C.; PEREIRA, C.R. Eficiência de uso de la radiación en soja en distintas fases fenológicas bajo estres hidrico. Revista Faculdad de Agronomia, La Plata, v.17, n.1, p.63-66, 1997.

KUMAR, P.V.; SRIVASTAVA, N.N.; VICTOR, U.S.; RAO, D.G.; RAO, A.V.M.S.; RAMAKRISHNA, Y.S.; RAO, B.V.R. Radiation and water use efficiencies of rainfed castor beans (Ricinus communis L.) in relation to different weather parameters. Agricultural and Forest Meteorology, Amsterdam, v.81, p.241253, 1996. 
MASCARENHAS, M.H.T. Competição de plantas daninhas com as culturas. Informe Agropecuário, Belo Horizonte, v.8, n.87, p.2632, 1982.

MELLO, H.B.; FERREIRA, L.R.; SILVA, A.A.; MIRANDA, G.V.; ROCHA, V.S.; SILVA, C.M.M. Interferência das plantas daninhas na cultura da soja cultivada em dois espaçamentos entre linhas. Planta Daninha, Viçosa, v.19, p.187-192, 2001.

PENGELLY, B.C.; BLAMEY, F.P.C.; MUCHOW, R.C. Radiation interception and accumulation of biomass and nitrogen by soybean and three tropical annual forage legumes. Field Crops Research, Amsterdam, v.63, p.99-112.1999.

SANTOS, J.B.; SILVA, A.A. Resistência de genótipos de Euphorbia heterophylla L. a herbicidas inibidores da enzima acetolactato sintase (ALS). Viçosa: Universidade Federal de Viçosa, 2000.37p. (RelatórioPIBIC/CNPq)
SILVA, A.A.; SILVA, J.F.; FERREIRA, F.A.; FERREIRA, L.R. Controle de plantas daninhas. Brasília, DF: ABEAS, módulo 3, 2000. 260p.

VARGAS, L.; SILVA, A.A.; BORÉM, A.; RESENDE, S.T.; FERREIRA, F.A.; SEDYAMA, T. Resistência de plantas daninhas a herbicidas. Viçosa: JARD, 1999. 131p.

VIDAL, R.A.; TREZZI, M.M. Análise de crescimento de biótipos de leiteira (Euphorbia heterophylla) resistentes e susceptível aos herbicidas inibidores da ALS. Planta Daninha, Viçosa, v.18, n.3, p.427-433, 2000.

VIEIRA, C. Período crítico de competição entre ervas daninhas e a cultura do feijão (Phaseolus vulgaris L.). Revista Ceres, Viçosa, v.17, n.94, p.354-367, 1970. 